\title{
Technology-Enhanced Problem-Based Learning Methodology in Geographically Dispersed Learners of Tshwane University of Technology
}

\author{
Sibitse M. Tlhapane* \\ Adelaide Tambo School of Nursing Science, Faculty of Science, \\ Tshwane University of Technology, Private Bag X 680, Pretoria 0001, \\ Republic of South Africa \\ E-mail: tlhapanem@tut.ac.za \\ *Corresponding author
}

\section{Sibongile Simelane}

Directorate Teaching and Learning with Technology, Tshwane University of Technology, Private Bag X 680, Pretoria 0001, Republic of South Africa

E-mail: simelanes@tut.ac.za

\begin{abstract}
Improving teaching and learning methodologies is not just a wish but rather strife for most educational institutions globally. To attain this, the Adelaide Tambo School of Nursing Science implemented a Technology-enhanced Problem-Based Learning methodology in the programme B Tech Occupational Nursing, in 2006. This is a two-year post-basic nursing program. The students are geographically dispersed and the curriculum design is the typically student-centred outcomes-based education. The research question posed by this paper is: How does technology-enhanced problem-based learning enhance student-centred learning, thinking skills, social skills and social space for learners? To answer the above question, a case study with both qualitative and quantitative data was utilised. The participants consisted of all students registered for the subject Occupational Health level 4. The sample group was chosen from willing participants from the Pretoria, eMalahleni and Polokwane learning sites, using the snowball method. This method was seen as appropriate due to the timing of the study. Data was collected using a questionnaire with both open and closed-ended questions. An analyses of the students' end of year examination was also done, including a comparison of performances by students on technology enhanced problem-based learning and those on problem-based learning only. The findings revealed that with Technology-enhanced Problem Based Learning (PBL), students' critical thinking, problem solving, and social skills improved and that social space was enhanced. This was supported by improved grades in students' on Technology-enhanced PBL as compared to those on PBL only.
\end{abstract}


Keywords: Technology-enhanced, Problem-based learning, geographically dispersed.

Biographical notes: SM Tlhapane is a senior lecturer at the Adelaide Tambo School of Nursing Sciences. She has an honours degree in nursing education, M Phil in Applied Ethics and certificates in both emoderation and e-assessment. Mrs Thapane has presented several papers at conferences on nursing and innovative teaching methodologies including e-learning.

Sibongile Simelane is an Instructional Designer have obtained the following Higher Diploma in Education (Computer literacy), Bed (HONS) in Computer Based Education and Master in Educational Technology. I have obtained a Blackboard Certified Trainer, e-Moderation certificate and Efficient Online Tutoring at e-Learning Africa Certificate. I have published several articles on elearning.

\section{Introduction}

It is the wish and strife of nursing education institutions in South Africa and all over the world, to improve their teaching and learning strategies in order to produce graduates who are well grounded in critical thinking, problem solving, creativity and up-to-date technological skills. In this country, this was actually enforced by the first White Paper on the Transformation of Education in 1999. This resulted in the advent of an outcomesbased curriculum by the Department of Education. Outcomes-based education (OBE) is a student-centred learning methodology. According to Lubisi, Parker and Wedekind (2002), OBE implies focusing and organising a curriculum around what is essential for the learners to be able to do at the end of their learning experiences. Teaching and assessment is organised in such a way that this learning ultimately happens. It is a paradigm shift from the traditional teaching method, or to be specific, the lecture method.

In 2004, the Adelaide Tambo School of Nursing at the Tshwane University of Technology implemented an OBE curriculum incorporating Problem Based Learning (PBL) in the programme, B Tech Occupational Nursing. This is a two-year post-basic nursing program. PBL is a curriculum design and a teaching/learning strategy which simultaneously develops higher-order thinking, disciplinary knowledge bases and practical skills by placing students in the active role of problem solvers confronted with an ill-structured problem that mirrors real-world problems. According to Yen (2006), in PBL, the acquisition of professional knowledge is as important as the development of problem-solving skills, abilities and social skills. Implementing PBL has its challenges and it is these challenges that led to the incorporation of technology into the B Tech Occupational Nursing programme of Tshwane University of Technology to enhance teaching and learning practices.

The research, on which this article is based, commences with the background of the study followed by the problem statement and rationale of the study. The literature reviewed is discussed and the research methodology followed described. The findings are discussed and the article concludes with a conclusion and recommendations. 


\section{Background to The Study}

Training academic staff members in PBL methodology and Outcome Based education (OBE) curriculation was part of an institutional development projected funded and directed by the Netherlands government. The training included tutorial skills, task formulation, assessment skills, block construction, and compilation of a tutor manual. The training project was evaluated and found to be effective. Implementing PBL was challenging because the students are geographically dispersed and attend part time. There were also infrastructural challenges in these off-campus venues, including lack of learning resources. Though the school did not go for a 70-100\% PBL methodology, we still had to meet certain requirements for the project to succeed. A pilot study on the implementation of the PBL methodology was done and this culminated in introducing the Blackboard learning management system (online) and an interactive CD-ROM to support the PBL methodology. It was hoped that this would improve the availability of literature and additional learning material for students so that the learning needs, including critical thinking and social skills could be met. For these skills to be developed the learners needed a social space, be it online or face-to face, where they could feel free to express themselves and engage in dialogue with one another.

The Blackboard course consisted of tools such as discussion, assignment, media library, web-links and learning content. Various activities were designed to keep the interaction between student and content, student and student as well as student and lecturer. The e-Games were designed in StudyMate and uploaded on the blackboard course as well as the CD-ROM. Assessments were designed in Respondus. Both these activities are for students' self-assessment to reinforce the content and promote active learning. These enhanced the student centered approach to learning. In addition to the above, there are files with checklists for various activities and learning modules. Volery and Lord (2000) assert that online delivery provides students and lectures with opportunities to collaborate online and to interact synchronously and asynchronously by means of a virtual online classroom. Each module has a purpose statement, frequently asked questions, learning outcomes, assessment criteria, prescribed hours and lecture notes. In other words, the files contain all information which is in the block book with the exception of the cases. This was done to make the online learning material self-sufficient. The student does not need to use the block book when on line unless it is referred to. The PBL case presentations are done face to face so the online discussion tool is used for general discussions especially on controversial topics.

Catney and Curie (1999) conducted a study on the effect of PBL supported by web-based learning on students at the College of Pharmacy, University of Iowa. They found that the students on PBL performed much better than the preceding students who were not on PBL. They further report that students' learning was not adversely affected by PBL. In fact, the PBL with web-based support was reported as being "personally and professionally rewarding" (Catney \& Curry, 1999:103). Another study was conducted by Chen and Lee (2006) at Chun Shang Medical School in Taiwan. According to their findings, students were not very satisfied with their performance but felt they had improved in self-confidence. Students showed a sense of autonomy and self-criticism. Tutors were satisfied with the students' performance though students scored low on one aspect, namely the use of the internet for resources.

All the above-mentioned factors, including the definitions of PBL and OBE by Lubisi et al. (2002) and Yen (2006) respectively are a starting point regarding motivation for the study. 


\section{Literature Study}

\subsection{Problem-Based Learning}

Problem-based learning is associated with constructivist learning. Savery and Duffy (1995) explain constructivist theory in terms of three principles. Firstly, constructivist theory states that understanding lies in our interaction with the environment. The core of constructivism is that understanding is an individual construction. The above-mentioned two authors further state that we cannot share understanding but we can test the compatibility of our understanding of phenomena. The second principle deals with the role played by stimulus in learning. Learning is stimulated and organised by puzzlement or cognitive conflict. This stimulus is the purpose or goal of the learner. The goal determines what the learner must learn and how he/she should learn. In other words, the learner is there because there is something he/she wants to achieve. The third and last principle states that knowledge evolves through social negotiation and the evaluation of one s' understanding. Collaborative groups are important because we can examine our own understanding and the understanding of others. Views of others challenge us and stimulate us toward new learning.

In line with the above statement on constructivist learning, Chickering and Ehrmann (1996) identify seven principles of good practice in teaching, namely encouraging contact between students and staff, reciprocity and co-operation between students, active learning, prompt feedback, and emphasising time on tasks, high expectations and respect for diverse talents. These are inherent in the PBL methodology. PBL methodology, according to $\mathrm{Ng}$ Yin Ho and Chan Chew Fook (1999) develops higher-order thinking skills. These include analysis, synthesis and evaluation. For these skills to be acquired by learners, teachers have to accept new ways of doing things. There has to be much communication and questioning of each other to refine thinking. Students should take responsibility for their learning. Both the students and the teacher should understand and accept that the teacher is not a dispenser of knowledge but a facilitator.

According to Boud and Felleti (1997), PBL is not a teaching technique but a way of learning. The method is said to be consistent with the principles of adult learning and takes into account the need for teachers not just to teach 'well' but also to lay the foundations for a lifetime of continuing education, both formal and informal. In this approach, students work on problems in small groups of 8-14 guided by the tutor or facilitator. Ehlert (2004) describes PBL as follows:

...involves the use of complex 'real world' problems as stimulus and framework for learning. It is based on the premise that students will be stimulated to 'want to know' and solve the problem posed because it is presented in a context that simulates real world situation ... As the students engage in solving the problem, they develop critical thinking skills while learning content and skills essential to the course.

The above author cautions against educators letting PBL become mechanical. This, he explains, is when there is no in-depth analysis of problems. Teachers allow students to come with minimal information and knowledge to solve problems. This is caused by the approach and strategy adopted by educators in presenting the task. In other words, the quality of the tasks most probably determines the quality of learning that takes place. 


\subsection{Technology-enhanced Teaching and Learning}

Most well-endowed higher education institutions throughout the world have already integrated the internet, multimedia, web tools and other technologies in order to provide students with improved experiences of teaching and learning. Twigg (2003) argues that higher education institutions should improve and supplement their traditional courses by taking advantage of the internet, technology and multimedia. Others refer to technologyenhanced teaching and learning as e-learning, online learning and the virtual classroom. Technology-enhanced teaching and learning is a philosophy and methodology which incorporate information communication technologies in the learning environment.

Computer illiteracy still exist worldwide, therefore, students should be motivated to learn how to use the computer. One of the criticisms of computer-based instructions is that more time is spent in teaching the student how to use the computer than on the actual content of the programme. Knebel (2002) reports that in a survey of 1500 health professionals, learners indicated the preference for new technologies or methods that offer greater flexibility reflecting the limiting work time for the pursuit of educational activities. Ray and Day (1998) in their study on the effect of CD-ROM in training nursing preceptors at the Central University of Queensland, the CD-ROM was found to be inexpensive as compared to the printing of material. The CD-ROM met the needs of both rural and urban preceptors.

\subsection{Online collaboration and Social Space}

Garrison (2006) regards collaboration as a key component of a community of enquiry. He says collaboration must include communication or discourse that is purposeful, threaded and reflective (JAL 2006, 25). In addition to the above he lists social presence and cognitive presence as important in the design facilitation and direction of collaborative learning experiences. According to Curtis (2001) the Blackboard Classroom provides a consistent interface for interactions in online learning though it needs some minor adjustments. He likens his findings with those of Johnson and Johnsons' (1996) which state that that there is a commonality between collaborative behaviors in face-to-face situations and online situation. The only difference is that, he states, the online environment has challenges arising from the limitations of the communication tools. This leads to more planning activities by the online group.

Chong Yaut Lee (2007) defines social space as a network of social relationships amongst social groups. Social space is characterised by three dimensions which include a warm online atmosphere, group cohesiveness and group participation. The warm online atmosphere is a social relationship amongst the online group members. In an online group discussion, students learn to collaborate, draw insights from different perspectives to the issues discussed. The group cohesiveness and the feelings of face-to-face interaction intensify the flow of information among the participants while encouraging support and commitment to group goals and cooperation. Group participation is enhanced when the social space is high (Chong Yaut Lee, 2007). 


\section{Problem Statement and Rationale}

Introducing innovative teaching methodology including technology and PBL is a paradigm shift for both the learners and the teachers. The students take responsibility for their learning whilst the lecturers step back and become facilitators. This is a radical change which requires patience, flexibility and expertise in handling the process. As stated earlier, preliminary evaluation of PBL at Adelaide Tambo School of Nursing Science revealed the inadequacy of library material and learning material. The lack of communication between lecturers and students and amongst students themselves was also revealed. A further problem is that students are geographically dispersed and have minimal contact with lecturers. Students for example have contact with the lectures and visit the institution only once a month and are fully employed.

Some studies report that PBL does not have a significant effect on students learning but a study from Middlesex University reports on negative results. An experimental design was carried out by Newman (2004) with nurses on a part-time continuing education programme. The experimental group was briefed beforehand about the study. Key findings were that the experimental group reported low levels of satisfaction and high levels of drop out. The study did not identify any important benefits or dis-benefits from PBL. However, the researcher concedes that the findings may be specific. He therefore recommends that other studies be done in other settings and contexts, using different research instruments. The above is enough motivation for our study because our students are also part-time nurses following the continuing nursing education programme. This together with preceding discussions led us to the research question which follows.

\section{Research Question:}

How does technology-enhanced problem-based learning promote student-centred learning?

Sub-questions:

- Which thinking skills, social skills and social space are provided by technologyenhanced PBL?

- How do students perceive technology-enhanced PBL?

- What are the effects of technology-enhanced PBL on student' performance?

\section{Research Methodology}

To answer the above questions, a case study consisting of both qualitative and quantitative data was conducted with students registered for the B Tech Occupational Nursing course at various learning sites of Tshwane University of Technology. White (2005, p.80) states that qualitative research deals with data that is mainly verbal, and that it helps one to understand social phenomena from the point of view of those who participate in them. He argues that the aim of qualitative research is to understand reality by identifying the meanings that people attach to specific thoughts, events, emotions and relationships. 
The total number of students enrolled for the course Occupational Health 4, was 120 and the sample number was 35 . The sampling method used was snowball, because students attend part-time and are geographically dispersed. Data was collected using a questionnaire with both open-ended and closed-ended questions. Participation in the study was voluntary. Data was analysed manually using, themes, quotes and categories. An analyses of the summative assessment was also done including a comparative analyses. The comparison was between two campuses: one implementing technologyenhanced PBL and the other implementing PBL only.

\section{Findings and Discussions}

The following findings are to be seen from a contextual point of view. Participants consisted of 33 females and 2 males. Their ages ranged between 25 and 46 and the Mode age 39-46 and the majority had professional experience of 10 years and more, thus enhancing the validity of the findings.

\subsection{Participants' Perceptions About The Blackboard Learning Material.}

Twigg (2003) states that technology is utilised in most higher education institutions as a new way of making the teaching and learning experience more powerful and accessible. For most participants, accessing online learning material was a first-time experience, making an assessment of their perceptions about the blackboard very appropriate. Mc Loughlin and Luca (2006) say student perceptions of technology are a major influence on their attitude and approach to learning. Thus, information technologies can change the quality of the learning experience, and can be used to create authentic environments for assessment. On the other hand, negative perceptions about technology, including technophobia, can be an obstacle to quality teaching and learning. It is important that students be in the right state of mind about technology, including motivation, and also have all barriers to technology access overcome.

Most participants in our study found going online exciting. They were surprised at the amount of information on the internet. One participant said "I did not know that there are such volumes of information on line". Marra (2004) reports that student become responsible for their own learning in the online environment and so are able to actualise deeper levels of learning. Students in a study by Marra (2004) reported that this kind of self-reliance in combination with online courses improved their capacity to learn. They were more confident about learning technological skills on their own. Most interesting was participants' different views about the PowerPoint lectures. One participant said, "the lecture notes are good" whilst others described them as being "just to the point". One participant described the lecture notes as "just a summary" whilst the other said the notes were "too brief". Another said, "I enjoy the hyperlinks on the lecture notes; they make life very easy for us". One participant said, "I have learned how to use the computer and the internet effectively".

Most participants said they enjoyed the e-Games. The important point which the participants mentioned was that the online learning material helped them in preparing for the next contact, and also in making up for the missed contact. Participants in our study confirm what Katz (1999: 5) found namely that educational service can be delivered through computers and network "to anyone, at any time and in any place". Participants indicated that the learning material in Blackboard is available 24/7. Few students expressed frustrations with the technology. These ranged from lack of internet cafes in 
rural areas to bandwidth problems. Only one student saw online learning as costly though she did not elaborate on that. One can attribute such perceptions to poor computer skills because most participants regarded on-line learning as costly in the beginning but as they got used to the computer it became less costly because they could go straight to what they were looking for.

To confirm what the participants said about the online course, for example accessibility, availability of information, etc, we have used the tracking tool from 01 March 2009 to $31^{\text {st }}$ July 2009 to draw the data on the tools usage in the course. In Figure 1 below, the tool usage by the students in the Blackboard course is presented.

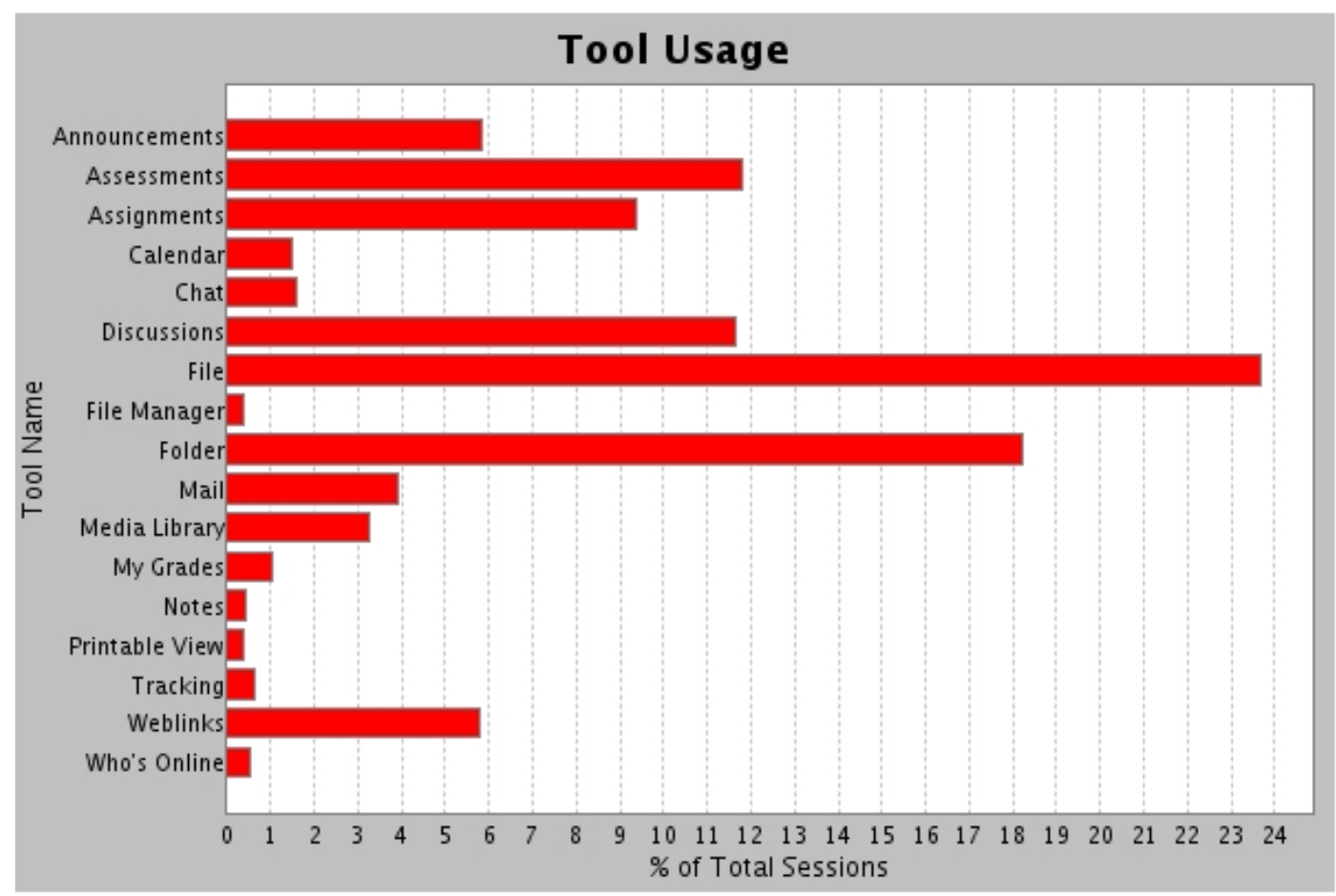

Figure 1. Tool usage by the students in the Blackboard course

Looking at figure 1. above it is evident that students used mostly files and folders because these contain the learning content. Assessments reflected above is students self assessment test.

\subsection{Participants' Perception About Technology-enhanced PBL}

Participants expressed satisfaction with the orientation they got for the PBL methodology and computer training. They used expressions like it was excellent, more than sufficient. One participant mentioned that it was just minimal. The majority of the participants indicated that the block books gave them enough guidance on the PBL methodology. Generally, the participants expressed satisfaction and said PBL was:

Very interesting

Kept me up to date

Very useful 
I was able to prepare for the next lecture

$P B L$ gave me direction about the curriculum

The learning outcomes were easy to follow

\section{Placed more emphasis on the student}

All participants said feedback sessions were valuable, most saying the quality of the group discussions was excellent. The majority of the participants reported that since studying in the PBL methodology, their self-confidence has improved. 16 of the participants reported that their elf confidence improved from low to average whist 9 reported improvements from low to high and 7 reported improvements from average to high. One of the participants indicated that: I now approach a problem confidently and with understanding. The other participant said I could easily recognise my strong points. Another participant stated that $P B L$ taught me to be responsible enough to utilise every single moment of studying. On the other hand, three participants indicated that their selfconfidence dropped from high to average. This is supported by comments such as I have learned that one cannot always know everything. I have learned to consider others' input. I now see the need to consult.

To enhance self-directed learning, the Blackboard course has been populated with several check-lists for various subjects and skills. Participants were asked for their views regarding the value of these check-lists and ten participants did not answer the question whilst two of the said they did not see any check-lists on the black board yet these have a button right at the look and feel (-homepage). Participants who responded said they found the checklists user-friendly and good testing tools. All but one said the check-lists guided them on what to study and how to master of certain skills like, for example, writing a research proposal. One participant said, the checklist made me go and read up and study, to be able to do it. Another said ...very good, help one to check whether we are still within what we are expected to learn. Another participant said, they are a source of guidance for my studies, they give me direction. Yet another said, those check-lists include almost the whole syllabus. One participant was excited with the checklists saying some (check- lists) are difficult but they are relevant to my studies"

\subsection{The Online Discussion}

According to Picciano (2002) the simplest definition of presence refers to a student's sense of being and belonging in a course; the ability to interact with other students and an instructor even though physical contact is not available. The discussion tool on myTUTor used to, amongst others, promote interaction between lecturers and students and amongst students themselves, thus enhancing the social space created by the PBL discussions. As stated earlier, these students are geographically dispersed in three provinces including Gauteng, Polokwane and Klerksdorp, with different cultures and socio economic background. In this space, students are brought together to form a community. The other term used for this online interaction is 'presence'.

The discussion tool on the black board are used to, as stated by Garrison (2006), stimulate reflective thinking and promote interaction between lecturers and students and amongst students themselves, thus enhancing the social space created by the PBL discussions. As stated earlier these students are geographically dispersed in dispersed in three provinces, namely Gauteng, Limpopo and the North West Provinces with different cultures and socio economic background. In this space, students are brought together to form a community. 
Savery \& Duffy (1995) claim that collaborative groups are important because knowledge evolves through social negotiation and the evaluation of one's understanding. In an on-line discussion, participants had to respond to this question: "Is nursing a profession, a career or just a job?" This is a topic digs into the students' critical thinking skills, practical nursing experience and personal growth or maturity within the profession. Interpersonal skills including assertiveness were also key skills required for the success of the discussion. From the whole group two powerful leaders emerged. The first one showed the passion she had for nursing. She described nursing as a profession and a career, more worth than gold. She motivated well for this stand point. She had support from most of the participants. The other one expressed, one would at face value say, the opposite of what the first one said. She argued that nursing was not a profession because nurses had no autonomy, status, nor legal leg to stand on. Though she did not state the reasons for such a conclusion, these became apparent from his support of this next participant.

One participant in the discussion did a critical analysis of both sites of the argument and came up with a constructive recommendation. She acknowledged the existence of legislation that controls nursing practice but argued that both nurses and employers were responsible for reducing nursing to just a job. She stated that both the Nursing Act and the regulations regarding the Scope of Practice for nurses in South Africa reduced nurses to level of doctors' hand maidens. She also sited the problem of the low rate of publications from nurses, as one of the factors contributing to the low status of the profession. At the end of the discussions all parties realized the need to update their knowledge and skills, do research and publish articles. This was well supported by other participants, including the one who said nursing was not a profession. They all saw the need to actively participate in legislative issues affecting the nursing profession.

Most participants expressed the need for more online discussion sessions. They said with online discussion they were able to get information and help from students at other campuses. They said it made communication very easy and fast. Most participants said they were satisfied with the attitude of the participants. They described their colleagues as being respectful. In any case, as professional nurses, they are expected to behave appropriately.

Using Chong Yaut Lee (2007) description of a social space to evaluate the above online experience by students, one can say online discussion created a 'healthy' social space. The term healthy is used because the participants did not compromise quality for the sake of warm relations. The discussion created a platform where students could express their views well without the fear of creating tensions. One can say the discussion created a social space which allowed academic or professional dialogue. In fact warm relations must allow discern and different viewpoints.

\subsection{Technology-enhanced Problem-Based Learning and Thinking Skills}

In this study, all participants, but one stated that the tasks presented in the block books gave them a clear understanding of what occupational health is all about. Of participants, 34 said they strongly agreed that the tasks were difficult enough and that it stimulated them to think. The ultimate aim of nursing education is to improve the standard of patient care. One participant indicated that I used to look at clients in a superficial way but now I go deep into clients' problems and exclude other problems. The other participants said it leads me to more research and more thinking skills. It is this quest for more knowledge that leads the student to lifelong learning. 
PBL methodology is in line with what $\mathrm{Ng}$ Yin Ho and Chan Yew Fook (1999) refer to as higher-order thinking skills. These include analysis, synthesis and evaluation which are higher than understanding and which are crucial in problem solving. There has to be much communication and questioning of each other to refine thinking and to solve problems. All participants stated that their problem-solving skills had improved and they indicated that I now have a better approach to problem solving at work. Other participants mentioned that they are able to solve problems understandably and to handle problems in a practical way. Participants stated that PBL taught them to be objective and positive to get positive outcomes. Other participants said they learned how to use internet and library effectively and to follow steps when they solve a problem. It therefore became apparent that PBL developed students' problem-solving skills.

OBE puts special emphasis on critical thinking, problem solving and team work. Participants said their critical thinking skills had improved and stated the following:

I am now able to think laterally

One has to look critically at a problem

You can have more than two solutions to a problem

Approach a problem from different angles before coming to a final solution

One can now make good decisions.

\subsection{Technology-Enhanced PBL and Students' Performance}

Improvement in student learning has to be observed also in their performance especially summative assessment. A simple definition of assessment by Sieborger and Mackintosh (2004:5) is that it is measurement of the extent of learning in individuals. It would be naïve to conclude from the students' report that technology-enhanced PBL has been effective in improving on their learning. Though both the OBE curriculum and PBL methodology recommend comprehensive assessment, in this study we are going to report on the written examinations only. Because technology-enhanced PBL was not implemented on all our campuses, at the end of the year we compared the examination results of two campuses, one implementing technology-enhanced PBL, reflected as Campus A in table 1 below and the other implementing PBL only, reflected as Campus B. Though the Blackboard course is available for all students registered for the Program, the reason for not having implemented it (blackboard course) at Campus B was lack of capacity, i.e. no e-learning facilitator and no computer laboratory at this campus or anywhere nearby where students could get initial training in basic computer skills or just an orientation to computers. Even when tracking students we found that students at this campus were not utilising the Blackboard course.

The exam policy at our institution states that all student doing the same subject should be subjected to the same assessment tool be it formative, continuous or summative assessment. So the comparison table below is performance in the summative assessment of one subject, Occupational Health 4. This was a three-hour paper consisting of both multiple-choice items and essay-type questions. Being a university of technology, the lower domains like recall and comprehension make up $25 \%$ of the questions, application level $50 \%$ of the questions and analyses to synthesis level, $25 \%$. Both the examination paper and the scripts were moderated by an external person.

The scores reflect the effectiveness of technology-enhanced PBL on students' performance. In Campus A there are more students who got $70 \%$ and above, whilst in Campus B there are more students whose results are below 60\%. Technology-enhanced 
PBL proved to be effective; hence, the methodology has been implemented at Campus B. (See table 1 below) the comparison of students result before the implementation of technology-enhanced PBL in Campus B. We also looked at the previous years' results and found that the pass rate in both campuses was also good but there were less $70-79 \%$ and more $50 \%-59 \%$.

Table 1. Comparison of students' in one subject

\begin{tabular}{|l|l|l|l|}
\hline \multicolumn{2}{|c|}{ Campus A Tech-enhanced PBL } & \multicolumn{2}{c|}{ Campus B PBL } \\
\hline Results in \% & Number of student & Results in \% & Number of student \\
\hline $80-89 \%$ & 1 & $80-89 \%$ & 0 \\
\hline $70-79 \%$ & 10 & $70-79 \%$ & 1 \\
\hline $60-69 \%$ & 15 & $60-69 \%$ & 15 \\
\hline $50-59 \%$ & 14 & $50-59 \%$ & 21 \\
\hline $40-49 \%$ & 2 & $40-49 \%$ & 3 \\
\hline Total & $\mathbf{4 2}$ & Total & $\mathbf{4 0}$ \\
\hline
\end{tabular}

In addition to the above comparisons we also looked at the students' performance on one compulsory 25-mark comprehensive multiple-choice questions of measuring various domain levels. Still in this question, the students at Campus A performed much better than those at Campus B. At Campus A, 67\% of the students obtained $50 \%$ and above, as compared to $42 \%$ of those at Campus B getting $50 \%$ and above. Following the above results technology enhanced PBL was implemented at Campus B. Students had to travel to Campus A for training in basic computer skills and orientation to the Blackboard course. The e-learning facilitator at Campus A also travelled to Campus B for student contact. The performance of the students in Campus B has since improved.

\subsection{Technology-enhanced Problem-Based Learning and Social Skills}

As Feng Yin (2006) argues that in PBL the acquisition of professional knowledge is as important as the development of problem-solving skills, abilities and social skills, so PBL requires collaborative work in learning and negotiation with others as part of the constructivist theory. In the OBE approach, the team 'teamwork' is used and this is also included in Chickering's seven principles including reciprocity and co-operation amongst students. Technology-enhanced PBL methodology should be carried out in a way that is consistent with the seven principles of effective pedagogy enunciated by Chickering and Ehrmann. Those principles are to encourage contact between students and lecturers, to develop mutual exchange and cooperation among students, to use active learning techniques, to give prompt feedback, to emphasise time on task, to communicate high expectation and to respect diverse talents and ways of learning. In this study, most of the participants said team members were helpful and respected one another. Few participants were not happy.

All our students have personal mobile phones which they use for communication with one another and also for communication with faculty members. Students prefer this to the email because with the mobile phone they get on the spot assistance. One can recall an incident when there was a system failure two days before the closing date for an online assignment. On that day one received more than 15 calls from desperate students. After 
telling them that they could submit the assignment on one's personal email they expressed a lot of appreciation and even passed the message to other students.

The quality of discussions amongst the participants was said to be good. One participant indicated: I learned that one needs to consult and one cannot always know everything. Other participants expressed their feeling as being exposed to other students and their expertise helped a lot and I learned to consider others' input. Another participant stated that PBL taught me that I must always consider others' input. All participants, with the exception of one, said they were satisfied with the contributions they brought to the discussions. Coming to what worked well in the group, the following were highlighted:

\section{Good communication,}

Keeping in touch,

Participation in discussions

Time management, respect

Teamwork, increased responsibility

Tolerance even when not satisfied

Information search and setting of rules

All the above, including the integration of technology in the course, indicate the social aspect of technology - enhanced PBL.

The above findings are encouraging, considering the fact that the students are geographically dispersed and all of them having full-time jobs. Not all students were happy with teamwork, and 5 students expressed the following frustrations:

Some students felt more important than others

Non-participation by others

Bunking classes if work not done

Based on the findings of this study one can argue that social space in education appears as to be dependent on other aspects of the students holistic development and interaction with the environment. These aspects include user friendly technology, student centered curriculum, critical thinking skills and social skills which are inherent in technology-enhanced PBL. Together they help students to understand, appreciate and utilize social space appropriately.

\section{Lessons Learned}

The blackboard is good with record keeping but always needs to be supported by other tools or technologies and also hard copies of records. This is based on one's experience with the other side of technology, which can be very distressing. The experience is that, having used the Blackboard for three years without any problems, one relied on it and learned a bitter lesson. Students had an assignment which was due 15th July 2009. Just five days before the closing date for submission, the assignment tool stopped taking attachments. Students could not submit assignments and thee lecturer could also not send marked and graded assignments back to the students. By the time the closing date for submissions came, the lecturer's personal email had about 100 assignments from 
desperate students who could not submit it on the Blackboard. On going into the Blackboard to check the graded ones there was nothing. The last resort was to contact the university's IT technician and the answer got was that there was corruption on the database and hardware which resulted in the file upload problem. To correct the problem, they had no option but to restore the data base from before the corruption occurred, hence the loss of all the marked and graded assignments. No amount of technology can replace the lecturer and the lecturer's responsibility for keeping up-to-date records remains.

Most students will not necessarily respond to anything on the blackboard unless there is an instruction from the lecturer regarding that, or the student has learned from other sources that the information is of immediate use in their learning. It is true that adult learners want information which is of immediate value to them. In our context, some students still need to be reminded to access the online material on their own because some of them, even if they are few, just do not participate in the online activities. The multimodal approach, with compulsory online activities, can be one way of getting student to be familiar with online learning. This point to the importance of communication between lecturer and students and the fact that the lecturer's role is just as important in e-learning as it is in traditional teaching methods.

\section{Conclusion}

This article has highlighted how the Adelaide Tambo School of Nursing at TUT overcame the challenges encountered by nursing education institutions globally. The Adelaide Tambo School of Nursing made an effort to contribute to the improvement of its teaching and learning strategies by incorporating the technology-enhanced PBL methodology. This was accomplished in order to produce graduates who are critical thinkers, skilled problem solvers, and technologically inclined. From this study, it is evident that technology-enhanced PBL helps students to develop social skills including, including self-confidence and self-criticism which are also part of life skills. Students appreciated the social presence provided by the technology-enhanced course. The high students' dissatisfaction and dropout rate reported by Newman (2004) were not observed in this study. Instead, the students' grades improved. One can also say the incorporation of technology made a difference because PBL needs more resource learning and the internet is valuable in this regard.

\section{Recommendations}

- We recommend that any institution that implements PBL to geographically dispersed learners with part-time contact sessions incorporate the use of information communication technology.

- To implement this successfully, resources are needed for both staff training and the purchase of teaching and learning material including technology.

- It is crucial for both staff members to be motivated to accept or to buy into this paradigm shift to technology-enhanced PBL, especially in the field of nursing.

- Other institutions in the developing countries should take embrace technology and integrate it in their teaching and learning. 


\section{References}

1 Botha, C., \& Simelane, S. (2007) The influence of e-learning on students' success rates in Human Resource Development. Proceedings of the 9th Annual Conference on World Wide Web Applications 5-7 September, Johannesburg, South Africa, 4-17. (http://www.zaw3.co.za).

2 Boud, D., \& Felleti, G. (1997). The challenge of problem-based education. Second edition, London: Kogan Page.

3 Catney, C., \& Curie, J.D. (1999). Implementing problem-based learning with WWW support in an introductory pharmaceutical course. American Journal of Pharmaceutical Education, 63(Spring), 97-103.

4 Chen, J.Y., Lee, M.C., Lee H.S., Wang, U.C., Lin, L.Y. \& Yang, J.H. (2006). An online evaluation of problem-based learning. Annals Academy of Medical Singapore, 624-633.

5 Chickering A, \& Ehrmann S.C. (1996). Implementing the seven principles: Technology as lever. AAHE Bulletin, October, 3-6.

6 Chong Yaut Lee, L. (2007). Social Space in Online Forum. Digital Learning, http://www.digitallearningin/srticle-details. Retrieved 15/07/2008.

7 Curtis, D.D., \& Lawson, MJ. (2001). Exploring Collaborative Online learning, Journal of Asynchronous Networks, 5(1), 21-33.

8 Ehlert M. (2004). Evaluation of problem-based learning methodology. North Western University. www.cotf.edu/ete/teacher/teacherout.html. Retrieved $15 / 07 / 2008$

9 Feng, Y. (2006). Applying methods of formative and summative assessments to problem-based learning in computer courses. China Papers Nov 2006 from http://science.uniserve.edu.au/pubs/china/vol6/IT2.pdf. Retrieved 15 /12/2008.

10 Garrison, D.R. (2006). Online Collaboration Principles. Journal of Asynchronous Networks. www.sloans-c.org/publication/jal/vloni3. Retrieved 12/04/2009

11 Katz, R.N. (1999). Dancing with the devil: Information technology and the new competition in higher education (First ed) San Francisco: Jossie-Bass.

12 Knebel, E. 2002. The use and effect of distance education in health care. Quality Assurance Project, 2(2).

13 Lubisi C., Parker B., \& Wedekind, V. (2002). Understanding outcomes-based education: Teaching and assessment in South Africa. Cape Town: SAIDE Oxford.

14 McLoughlin, C., \& Luca, J. (2006). Quality in online delivery: What does it mean for assessment in e-learning environments, meeting at the crossroads Available at http://ascilite.org.au/conference/melbourne01/mcloughlin2.

15 Marra, R.M. (2004). An online course to help teachers to use technology to enhance learning: Success and limitations http://proquest.umi.com/pdqweb?did=757578841\&sid=12\&Fmt=4\&clientld=36149 \&RQT $=309 \& V N a m P Q D . ~ R e t r i e v e d 14$ December 2005.

16 Newman, M. (2004). Problem-based learning: An exploration of the method and evaluation of its effectiveness in a continuing nursing education programme. Research Program Executive Report. 
17 Ng, Y.H.P., \& Chan, Y.F. (1999). Teaching and learning via IT: Higher order thinking skills in English Language, English Literature and Mathematics, Available at www3.moe.edu.sg/edumall/mpite/edtech/papers/f3 pp2-3. Retrieved 22/07/2008.

18 Picciano, A. (2002). Beyond student perceptions: Issues of interaction, presence, and performance in an online course. Journal of Asynchronous Learning Networks 6(1), 21-40. http://www.aln.org/publications/jaln/v6n1/v6n1_picciano.asp. Retrieved 3/3/ 2008.

19 Tan, W. (2004). Research design 1: Case studies in practical research methods. (2nd ed.) Jurong: Prentice Hall.

20 Ray, C., \& Day, J. (1998). Students' attitude towards electronic information resource. Information Research, 4. Available http://www.informationr.net.ir/4-2/paper54.html. Retrieved: 20 /11/ 2007.

21 Republic of South Africa. (2004). White Paper on e-Education: transforming learning and teaching through information and communication technologies. Pretoria: Government Printer.

22 Savery J.R., \& Duffy T.M. (1995). Problem-based learning: An instructional model and its constructivist Framework. http://crlt.indiana.edu/publications/duffy_publ6.pdf pp 35-38.

23 Sieborger, R., \& Macintosch, H. (2004). Transforming Assessment: A guide for South African Teachers, 2nd edition, Cape Town: Juta.

24 Twigg, C. (2003). Change. Improving quality and reducing cost; design for effective learning.

Available http://www.proquest.umi.com/pdweb?did=592388111\&sid=10\&Fmt=3\&clientld=2 1888\&RQT=309\&VName=PQD. Retrieved: $20 / 11 / 2007$.

25 Volery, T., \& Lord, D. 2000: Critical success factors in online education. The International Journal of Educational Management, 14 (5), 216-223.

26 White, C.J. (2005). Research: A practical guide. Pretoria: Intuthuko. 